\title{
Do discurso monológico da consciência aos gêneros do discurso
}

\author{
From monologic discourse of consciousness \\ to discourse genres
}

Maria Marta Furlanetto*

Universidade do Sul de Santa Catarina

RESUMO: Neste trabalho procuro traçar um painel para contextualizar a importância epistemológica da concepção dialógica e da concepção estendida de gêneros do discurso em Bakhtin e suas implicações e consequências para a vida comunitária, com ênfase para a ética. O painel se desdobra para a apresentação de um nicho em que os gêneros do discurso funcionam como uma unidade de conhecimento que só faz sentido como prática social. A partir daí algumas implicações são apontadas com relação à relevância deles em nossos atos cotidianos, com ênfase para os de caráter profissional, com base na análise e reflexão sobre experiências de sucesso e de fracasso, consideradas as categorias pragmáticas da arquitetônica de Bakhtin.

PALAVRAS-CHAVE: Discurso; monologismo; dialogismo; gênero.

ABSTRACT: In this work I present a tentative panel for the contextualization of the epistemological significance of the dialogical concept and of the extended concept to the genres of discourse in Bakhtin, and their implications and consequences for communal life, with an emphasis on ethics. The panel unfolds to present a niche in which genres of discourse work as a unit of knowledge that only makes sense within social practice. From that point I call attention to some implications in relation to their relevance along our quotidian acts, especially those acts of professional character, based on the analysis and reflection on experiences of success and failure, considering the pragmatic categories of Bakhtin's architectonics. KEYWORDS: Discourse; monologism; dialogism; genre.

[...] un orateur qui s'écoute parler est un mauvais orateur; un professeur qui ne s'occupe que de ses notes est également un mauvais professeur. Ils désamorcent eux-mêmes l'impact de leurs propos, ils brisent le lien vivant, de nature dialogique, qui les unit à leur auditoire et, ainsi, ils déprécient eux-mêmes leurs propres prestations.

(Voloshinov, La structure de l'énoncé)

*mmarta@intercorp.com.br 


\section{Introdução}

Parto do princípio de que o multifacetado contexto históricoepistemológico em que foi gerada a abordagem dialógica da linguagem é uma tela (ou teia) que se deve perscrutar para que se compreenda a significância da concepção estendida de gêneros do discurso em Bakhtin e seu Círculo e suas implicações e consequências para a vida comunitária, com ênfase para a ética. O painel que desenho aqui compóe-se de alguns fragmentos selecionados que são evocados para emoldurar um nicho em que os gêneros do discurso representam uma unidade de conhecimento na prática social (na comunicação discursiva). A partir daí aponto algumas implicaçóes da relevância dos gêneros em nossos atos cotidianos, com ênfase para os de caráter profissional.

Esta reflexão é só um ponto numa sequência de trabalhos em que tenho buscado, na interface da cultura vivida, compreender os laços em sua materialidade e trabalhar o distanciamento e a aproximação do outro (sujeito), materializando aquele movimento de escuta para compreensão e retorno para a manutenção de duas consciências (compreender o outro sem assimilar-se a ele). Aqui estou pensando seletivamente nas relações pedagógicas, e a questão que se apresenta, então, está razoavelmente sintetizada nas seguintes asserçóes de Bakhtin:

A palavra do outro coloca diante do indivíduo a tarefa especial de compreendê-la (essa tarefa não existe em relação à minha própria palavra ou existe em seu sentido outro). (BAKHTIN, 2003, p. 379)

Desde o início o falante aguarda a resposta deles [os outros], espera uma ativa compreensão responsiva. [...]. Um traço essencial (constitutivo) do enunciado é o seu direcionamento a alguém, o seu endereçamento. (BAKHTIN, 2003, p. 301, grifos do autor)

[...] viver significa ocupar uma posição axiológica em cada momento da vida, significa firmar-se axiologicamente. (p. 174)

Esta reflexão é também, para mim, ponto de referência para um percurso indefinido, sempre inacabado.

\section{Fragmentos de um mosaico}

Em uma conversa com Foucault (datada de 1972) sobre os intelectuais e o poder, na obra Microfisica do poder (FOUCAULT, 1989), Deleuze rememora as relaçôes "teoria / prática" e o modo político-social de vivê-las, afirmando 
genericamente que "ora se concebia a prática como aplicação da teoria", ora como "devendo inspirar a teoria"; de todo modo, ele via essas relaçôes, na ocasião, "como um processo de totalização", sugerindo em seguida que essas relações "são muito mais parciais e fragmentárias." (apud FOUCAULT, 1989, p. 69).

Deleuze manifesta, nessa conversa, que uma teoria não se desenvolve sem encontrar um muro pela frente, sendo a prática a chave para atravessar o muro. Mas a prática não se oferece como aplicação da teoria: diria, a partir de Deleuze, que aí há muitos sujeitos em ação, formando rede - e não meramente um comandante e seus comandados, estes necessitando das ordens e valores alheios, da consciência alheia (unificada) para entrar no regime de um saber.

Dada essa nova forma de relação, a própria "teoria" não é senão uma prática (prática teórica). Aqueles que estão concernidos por uma teoria têm de falar por si próprios - essa é a forma de contornar e impedir que o poder se torne absoluto (por silenciar).

Com relação a essa questão, marcada pelo modo de envolvimento dos sujeitos humanos entre si, nas práticas sociais, e que representa o pano de fundo desta discussão, permito-me apresentar um contexto religioso.

Evoco Ellerbe (1995, p. 15-16), com referência à manobra política, no período de 200 a 500 da era cristã, para fazer o cristianismo palatável aos romanos. Os critérios básicos da Igreja Católica para considerar alguém um cristão eram: fazer a confissão do Credo, aceitar o batismo, participar do culto, obedecer à hierarquia da Igreja e acreditar que a única verdade era aquela proveniente dos apóstolos e legada pela Igreja. A uma pessoa ignorante bastaria crer - sem nada entender - e escutar as autoridades. Foi posto à sombra, na ortodoxia, o argumento de que um verdadeiro cristão só seria identificado por seu comportamento e maturidade - como lembrou Carl Sagan $(2008$, p. 51) em uma de suas palestras: "Se um Deus Criador existe [...], vai preferir um bronco que adore sem nada entender?"

No período da Reforma Protestante e da Contra-Reforma católica, protestantes e católicos diminuíram o importante papel da comunidade como instância de harmonia e vitalidade: a Reforma desencorajou as irmandades, que davam provimento aos membros em tempos difíceis, organizavam celebrações e jogos, cuidavam dos pobres e estabeleciam hospitais; o catolicismo privatizou o ato público de perdão dos pecados, marcando o retorno do pecador ao seio da comunidade, tornando esse ato uma questão a ser resolvida entre o indivíduo e o padre, no confessionário. Ao empenharem-se na conversão do povo, na unificação religiosa, protestantes e católicos tornaram mais fácil para a igreja e o Estado um controle mais direto do indivíduo (ELLERBE, 1995, p. 100). 
Também houve uma drástica separação para a humanidade com a dicotomia céu / Terra, pregada igualmente pelos dois cleros: Deus no céu, o demônio na Terra. Apesar da pregação, do medo imposto e dos castigos perpetrados, nenhum ensinamento real da religião penetrou nos chamados cristãos, especialmente na grande massa popular. Não se tratava de ensinar, mas de buscar e manter obediência estrita ao que os cleros entendiam ser a vontade divina.

Fica bem demarcado o mundo (forçado) do monologismo. "Do ponto de vista da verdade não há consciências individuais. O único princípio de individualização que o idealismo conhece é o erro." (BAKHTIN, 1997, p. 80). ${ }^{1}$ O "princípio monológico" é marca da Idade Moderna em todos os campos humanos, com reforço do racionalismo europeu, cultuando a Razão. Trata-se aí, conforme Bakhtin, de uma "profunda particularidade estrutural da criação ideológica da Idade Moderna” (1997, p. 81). Fosse apenas uma teoria, não teria alcance tão amplo, mas se espalhou indistintamente por todo o tecido social.

Cabe enfatizar que, quando Bakhtin estabeleceu conexões históricas entre Dostoievski e as primeiras manifestaçôes da cultura cristã (CLARK; HOLQUIST, 1998, p. 267), estava contrastando um cristianismo popular que vingava em comunidades multifacetadas e a forma de cristianismo que se enraizaria na Idade Média, com uma forçada estabilidade conseguida pelo triunfo dessa crença no mundo romano.

A oposição era entre uma época polifônica de variedade e conflito e uma era monológica de calma e unidade. [...] No princípio da Cristandade, um homem engajado, vibrante, apresentou-se, uma voz viva e em diálogo com outras pessoas e outras vozes. Mas, nos séculos subsequentes, ocorreu uma calcificação da palavra viva do fundador, uma perda de seu significado mais engajado, mais completo e mais presente. (CLARK; HOLQUIST, 1998, p. 268)

A Igreja e outras instituições buscam impor uma única linguagem da verdade / única linguagem correta, apesar de toda a variedade no fluxo da linguagem - a sua heteroglossia, representando aquelas energias que Bakhtin viu como centrífugas, em contraposição ao esforço de centralização, generalização e universalização (forças centrípetas).

${ }^{1}$ Bakhtin especifica que o conceito de verdade não decorre da necessidade de uma consciência única e una. Ela pode surgir da convergência de várias consciências. Assim, a forma monológica de percepção de conhecimento e da verdade é uma das formas possíveis, que surge quando "a consciência é colocada acima do ser e a unidade do ser se converte em unidade da consciência" (1997, p. 80). E aí temos as imagens do "eu absoluto", "consciência em geral", "espírito absoluto" - todas formas metafísicas, eclipsando a individualidade e a interatividade (1997, p. 79). 
A outra face da questão religiosa, a tradição quenótica (esvaziamento do divino), que aparentemente tinha o engajamento de Bakhtin, é o de "uma comunalidade radical (sobornost')" e, por implicação, o respeito pelas realidades materiais do dia-a-dia (CLARK; HOLQUIST, 1998, p. 108). O tipo de desenvolvimento da consciência amarrada à religiosidade ortodoxa do povo russo ocorre como consciência da relação de alteridade. E para Bakhtin é a linguagem que mantém a união da comunidade, que é sua materialidade, uma prática, um compromisso dentro das comunidades. Uma identidade não se representa como "mesmidade", mas como simultaneidade. É assim que o diálogo reúne "diferenças simultâneas" (várias consciências), como expressam Clark e Holquist (1998, p. 36). O que Bakhtin enfatiza é a dinâmica social da prática observável da linguagem, e é isso que estrutura as relaçôes interpessoais no "mundo da consciência intermédia". ${ }^{2}$

Fique entendido que não se trata, aqui, de aceitar Bakhtin como homem religioso ou buscar saber se ele o era. Hirschkop (2006, p. 148), em seu estudo sobre o sagrado e o secular em Bakhtin, Benjamin e Wittgenstein, deixa claro que "Bakhtin continua a ser um escritor que parece se utilizar de conceitos religiosos sem realmente pretender ser um pensador religioso."

Os poucos recortes reunidos acima são suficientes para mostrar o traço que me interessa aqui: o impedimento imposto (teórico e pragmático), que os contextos ideológicos institucionais entendem que seja correto, legitimado por normas estabelecidas, resultando daí, por extensão, que o trabalho institucional das pessoas envolvidas fique centrado no objetivo do monologismo, do formalismo, do idealismo; entretanto, há também uma tendência de superação. Na seção a seguir, estreito o canal de visão em direção a Bakhtin e ao Círculo.

\footnotetext{
${ }^{2}$ Além de outras personalidades das quais Bakhtin foi aproximado (Heidegger, Levinas, Merleau-Ponty), gostaria de indicar como candidatos o filósofo judeu alemão Eugen Rosenstock-Huessy (1888-1973), e o filósofo judeu tcheco Vilém Flusser (1920-1991), que viveu 30 anos no Brasil, onde publicou Lingua e realidade (1963). Com um estilo semelhante (não apegado ao academicismo), Rosenstock-Huessy, em $A$ origem da linguagem, ataca ousadamente um tema delicado nos estudos que envolvem a linguagem. Diferenças entre si à parte, não poucas passagens dos dois filósofos cruzam com os fios teóricos e filosóficos de Bakhtin, traçando fragmentos da grande rede intertextual estendida pela intelectualidade ao pensar, aqui e ali, as amarras humanas com a linguagem, o mundo e seus semelhantes. É um tema que pode ainda ser explorado, colocando lado a lado esses autores: a rede da conversação humana, a identidade pela diferença, a multiplicidade.
} 


\section{Uma compreensão do programa de Bakhtin}

Hebeche (2007), num ensaio filosófico centrado na análise que Bakhtin fez do romance polifônico de Dostoiévski, estabelece o núcleo da virada bakhtiniana relativamente à visão filosófica predominante no Ocidente - ou seja, a "saída da filosofia da consciência para uma mais abrangente compreensão do discurso". A referência que faço não visa ao ponto crítico da análise de Hebeche - "os resíduos monológicos da filosofia da consciência" -, mas precisamente ao grande salto que representa sua ultrapassagem do modelo metafísico em direção a uma filosofia "da faticidade existencial", conforme expressa o autor.

Ao falar do "discurso" em Dostoiévski, Bakhtin (1997, p. 181) especifica que, de fato, trata-se de discurso: "a língua em sua integridade concreta e viva e não a língua como objeto específico da linguística, obtido por meio de uma abstração absolutamente legítima e necessária de alguns aspectos da vida concreta do discurso". Bakhtin está se referindo ao ângulo dialógico de seu estudo, que só pode ser incorporado pelo que ele chama metalinguística (um estudo que não se sujeita àquilo que já está circunscrito, sistematizado, classificado). ${ }^{3}$ Trata-se agora do campo da vida. No discurso, manifestam-se "posiçōes de diferentes sujeitos". Uma consequência disso é que o enunciado ganha um autor.

A forma de autoria depende do gênero do enunciado. Por sua vez, o gênero é determinado pelo objeto, pelo fim e pela situação do enunciado. [...] Quem fala e a quem se fala. Tudo isso determina o gênero, o tom e o estilo do enunciado: a palavra do líder, a palavra do juiz, a palavra do mestre, a palavra do pai, etc. É isso o que determina a forma da autoria (BAKHTIN, 2003, p. 389-390).

Pontuemos ainda o caráter comunalidade, que é relevante para compreender a extensão do conceito de gênero. Em Vygotsky and Bakhtin on community, Wertsch (1998), tendo como ponto de partida a convergência das ideias de Vygotsky e de Bakhtin sobre os processos sociais, privilegiando a interação e o contexto, explora o conceito de comunidade:

Em vez de considerar comunidades preexistentes como originando instrumentos culturais tais como "gêneros do discurso" e "linguagens sociais" (BAKHTIN, 1986), a relação entre linguagem e comunidade é muito mais dialética. De fato, em larga extensão comunidades são vistas como ganhando

\footnotetext{
${ }^{3}$ Ao tratar do texto como dado primário das ciências humanas, Bakhtin especifica que sua análise é filosófica, e que a pesquisa "transcorre em campos limítrofes", nas fronteiras das disciplinas (2003, p. 307).
} 
existência por meio de e por causa da linguagem. Os problemas que desejo apresentar nessa conexão são: a) que espécie de comunidades estão envolvidas, e b) o que o ser membro delas significa (tradução minha).

Ele propõe, então, uma distinção entre comunidades implícitas e comunidades imaginadas - ambas fundadas na mediação semiótica, mas distintas na forma como os sistemas de signos funcionam na formação e reprodução da própria comunidade.

Sintetizemos a identificação dessas duas formas de comunidade para apreciar a relevância de sua proposição.

Uma comunidade implícita congrega sujeitos com um conjunto de ferramentas comum, mesmo desconhecendo esse fato e mesmo sem realizar qualquer esforço para criar ou reproduzir essa comunidade. Exemplo: uma comunidade de pessoas que utilizam um processador como o Microsoft Word para Macintosh. É claro que nada impede que haja esforço para transformar um grupo assim (disperso) em uma comunidade imaginada.

Uma comunidade imaginada pode ser exemplificada, em seu aspecto radical, por uma sociedade secreta que use certos instrumentos para reconhecimento mútuo dos membros (símbolos, senhas, elementos gestuais, e, claro, um sistema semiótico). Há, nesse caso, ênfase na manutenção e na reprodução dessa comunidade - daí a existência de procedimentos de iniciação e ritos de passagem. ${ }^{4}$

A diferença principal entre os dois tipos de comunidade é o papel e função dos instrumentos culturais envolvidos. Uma comunidade implícita é frouxa em sua organização, uma vez que não está direcionada para propósitos coletivos (mas pode ser vista como "matéria-prima" para a fundação de comunidade imaginada); uma comunidade imaginada projeta instrumentos para o reconhecimento e reprodução de um grupo social, tentando cimentar as relações dentro desse grupo em vista de metas específicas. ${ }^{5}$

Embora Vygotsky e Bakhtin não tenham escrito sobre esses tipos de comunidades ou comunidades em geral, Wertsch (1998) considera que ambos

\footnotetext{
${ }^{4}$ Wertsch inspirou-se na noção de "comunidade política imaginada", que Anderson utilizou para marcar o conceito de nação: Anderson, B. (1991). Imagined communities: Reflections on the origin and spread of nationalism. London: Verso.

${ }^{5}$ Ver o esforço de unificação da fé cristã durante o século IV, quando as narrativas sagradas sofreram um processo de seleção e edição para compor o que se entende por Bíblia (ELLERBE, 1995).
} 
fizeram asserções fundamentais sobre o mundo social e sua organização semiótica, que ele examina para dar uma ideia da postura que poderiam ter sobre comunidade. Nos escritos de Vygotsky, por exemplo, há ênfase no desenvolvimento conceitual por meio do letramento e do pensamento tecnológico, sugerindo uma comunidade implícita de pensadores tecnocraticamente proficientes. Diferentemente, Bakhtin punha em foco as formas de mediação semiótica distantes da tecnocracia e da racionalidade abstrata. Diz Wertsch: "Em sua análise da multivocalidade [...], ele focalizou a diferenciação e a estratificação que distinguem variadas comunidades de linguagem antes que amarras genéricas que unem pessoas em um grupo homogêneo, 'monológico"' (tradução minha).

Com referência a Bakhtin, é a questão da variação, da multivocalidade que amarra a ideia de comunidade ao objetivo proposto neste trabalho. A unicidade, em Bakhtin, só é encarada no sistema abstrato da gramática, isolada do mundo concreto e da conceptualização ideológica. Se há, estabelecida abstratamente (como sabemos), uma língua nacional unitária, ela só funciona por meio de uma multidão de mundos concretos, com múltiplos sistemas de crenças. E é nesse campo, como pontua Wertsch, que Bakhtin apresenta dois construtos distintos, mas empiricamente associados:

a) linguagens sociais, diferenciando grupos de falantes por seu estrato (profissional ou outro) em dado tempo e lugar (professores, matemáticos, físicos, japoneses, mulheres, europeus...);

b) gêneros do discurso, que diferenciam situações específicas e contextos de fala.

Assim, o foco de Bakhtin sobre as linguagens sociais e os gêneros do discurso - como "modelos tipológicos de construção da totalidade discursiva" (BAKHTIN, 2003, p. 334) - indicia uma pluralidade de sistemas de crenças sociais ligadas a sistemas verbais ideológicos. A questão essencial de Bakhtin era a heterogeneidade de perspectivas sobre o mundo (sistemas axiológicos de crenças), e formas de autoridade que distinguem uma comunidade de discurso de outra - apesar de que se trate, em sua teoria, de comunidades um tanto amplas.

Portanto, sem formalmente tratar do assunto, Bakhtin estaria voltado para a ideia de comunidades implícitas, mas contrastando com Vygotsky relativamente ao tipo de meta. Os gêneros enfatizariam a multiplicidade, e não a essencialidade, a mesmidade do comportamento de um indivíduo ou grupo. Nem Vygotsky nem Bakhtin, destaca Wertsch, visavam indivíduos ou grupos como dotados de algum atributo inerente causador de seu modo de pensar ou falar. Seu foco foram os processos contextuais envolvidos na produção dos 
enunciados - daí a relevância da incorporação de uma noção tal como a de gêneros do discurso, em Bakhtin, integrada nas comunidades de discurso.

Se Vygotsky e Bakhtin não disseram muito a respeito de comunidades imaginadas, a partir deles é possível, como considera Wertsch - o que se tem feito nos últimos anos - analisar as relações entre agentes e artefatos culturais que são empregados por eles como fonte de identidade, e como esses artefatos (incluindo textos em sua forma genérica) podem sustentar as comunidades imaginadas. Eu diria que o "chamamento" (apelo, chamada) é a forma geral de busca de aproximação para a formação e coesão das comunidades, com seus sócios, membros, adeptos, integrantes.

O conceito de comunidades imaginadas me parece análogo daquele proposto por Swales para "comunidade discursiva" (em contraste com "comunidade de fala"). 'Swales (1990, apud PIMENTA, 2007, p. 2030, 2031) contrapóe "comunidade de fala" e "comunidade discursiva" para eliminar certas controvérsias relativas à relação comunidade / discurso. Uma comunidade de fala (que aqui corresponderia a comunidade implícita) compartilha, certamente, de formas linguísticas, regras e conceitos culturais, mas o que predomina nela são as necessidades de socialização e de solidariedade do grupo, enquanto que numa comunidade discursiva (retórica) os objetivos vão muito além: predominam necessidades de comunicação vinculadas a seus objetivos de desenvolvimento e manutenção de características discursivas daquela comunidade, tendo-se o cuidado de incorporar e qualificar seus membros. Comunidades de fala também teriam a ver, no quadro da teoria de Bakhtin, com a esfera cotidiana de comunicação discursiva com seus gêneros primários, e comunidades de discurso se aproximariam das esferas institucionais, com gêneros secundários.

Bonini (1999, p. 305-306) assim apresenta o conjunto de características, conforme Swales, para identificar uma comunidade discursiva:

1) um conjunto de objetivos detectáveis; 2) mecanismos de intercomunicação entre seus membros; 3) um conjunto de propósitos que move os mecanismos participatórios; 4) uma utilização seletiva e evoluinte desses mecanismos; 5) um léxico específico em desenvolvimento e 6) uma

\footnotetext{
${ }^{6}$ Surgida nos anos 1980, a noção de comunidade discursiva progressivamente alargou seu sentido, e a partir dos anos 1990 se tornou um espaço de pesquisa bastante ativo (cf. CHARAUDEAU; MAINGUENEAU, 2002).
} 
estrutura hierárquica explícita ou implícita que controla o processo de entrada na comunidade e a ascensão dentro dela.

Então, o conjunto de indivíduos de uma comunidade discursiva tem "determinados hábitos comunicativos e conhecimentos linguísticos comuns, cuja comunicação se realiza mediante a utilização de gêneros textuais convencionados" (BONINI, 1999, p. 305).

Nos gêneros, por sua vez, com seus temas específicos desenvolvidos nas esferas sociais, há os constituintes ditos não-verbais - mas que, na ótica do enunciado, não são elementos meramente externos.

\section{O não-verbal - corpo, gestos, subgestos, subtons}

Qualquer enunciado verbal (em gêneros do cotidiano ou gêneros secundários), uma vez que concebido em função de uma interlocução (implicando compreensão e resposta), tem como complemento elementos extraverbais, e a resposta esperada também: o gesto, o sorriso, o movimento de mão, de cabeça... Voloshinov ([1930] 1981, p. 294) destaca que também o discurso interior, aparentemente em sua pura forma monológica, é de ponta a ponta dialógico: é atravessado pelas avaliações de um auditório virtual, potencial. Essa forma dialógica, diz ele, aparece claramente em momentos de tomada de decisão; aí, surge a hesitação e a necessidade de nos convencermos da justeza de uma decisão ou outra. Nesses momentos, haja consciência ou não, uma das vozes estará manifestando ponto de vista e avaliações de outrem, do mesmo espaço ideológico ou de outro. Um ponto de vista "pessoal", ademais, é formado a partir de outrem.

Essa orientação social do enunciado, portanto, é uma "força viva" que determina, em última análise, a forma estilística e a estrutura gramatical do enunciado - nos gêneros. Um criador de literatura, por exemplo, além das falas dos personagens, deve criar suas "maneiras" (boas e más), seu comportamento em sociedade, e isso é o que Voloshinov chama expressão gestual da orientação social do enunciado (1981, p. 299) - que se reflete nos estudos do ethos, que tematizo adiante, nesta seção. ${ }^{7}$

Para mostrar as sutilezas do discurso não-verbal que sustenta várias formas de implícito na experiência dramática do cotidiano em sua multifacetação

7 É nesse sentido que se pode dizer que a busca, num dicionário, dos sentidos das palavras e expressões não oferece garantia de compreensão de uma conversação. 
- como sugere Bakhtin ao enfatizar o acento apreciativo da comunicação discursiva -, trago uma peculiar proposta de estudo exposta em uma cena do romance $O$ homem duplicado, de José Saramago, e seu comentário pelo narrador. A cena é analisada em suas minúcias, explorando o acompanhamento do discurso verbal, que presume noções como: gesto, subgesto, implícito, ethos, tons, subtons. ${ }^{8}$

O narrador de Saramago no romance compara o subgesto às letrinhas miúdas de contratos:

É costume dizer-se [...] que Fulano, Beltrano ou Sicrano, numa determinada situação, fizeram um gesto disto, ou daquilo, ou daqueloutro, dizemo-lo assim, simplesmente, como se o isto, ou o aquilo, ou o aqueloutro, dúvida, manifestação de apoio ou aviso de cautela, fossem expressões forjadas de uma só peça, a dúvida, sempre metódica, o apoio, sempre incondicional, o aviso, sempre desinteressado, quando a verdade inteira, se realmente a quisermos conhecer, se não nos contentarmos com as letras gordas da comunicação, reclama que estejamos atentos à cintilação múltipla dos subgestos que vão atrás do gesto como a poeira cósmica vai atrás da causa do cometa, porque esses subgestos, para recorrermos a uma comparação ao alcance de todas as idades e compreensões, são como as letrinhas pequenas do contrato, que dão trabalho a decifrar, mas estão lá (SARAMAGO, 2006, p. 45-46).

Nesse romance, "gesto" não sai de sua área estrita, a gestualidade corporal. Mas, a comparação desses subgestos a "letrinhas" dissimuladas já dá um aval para a ampliação da noção. É assim que, do gesto do corpo, desde o ostensivo, que aponta diretamente, até o mais sutil, passamos aos gestos discursivos: gesto de leitura, de escrita, de interpretação. Gesto é um movimento, uma atitude, que irrompe significativamente desde que se entre num processo discursivo.

Na Análise do Discurso (AD), seguindo a orientação de Pêcheux, assumida por Orlandi, tem-se um dispositivo teórico voltado para a apreensão de "gestos de leitura", ou seja, análise e interpretação / compreensão de discursos

\footnotetext{
${ }^{8}$ Subtom - 1. cor suave, cor de um pigmento escassamente passado sobre uma superfície branca ou clara; transparência de cor, cor vista através (e modificada por) outra(s) cor(es); 2. conteúdo expressivo ou moral subjacente, implícito numa frase ou ação. Ex.: s. maliciosos em cada entrelinha. (HOUAISS, 2001). "Subgesto" não consta nesse dicionário.
} 
- mais especificamente, como os sentidos se produziram nesses discursos. Orlandi (1996, p. 18) explica que "a palavra gesto, na perspectiva discursiva, serve justamente para deslocar a noção de "ato" da perspectiva pragmática; sem, no entanto, desconsiderá-la”. ${ }^{9}$ A interpretação, para Orlandi, como gesto que é, é consequência da incompletude da linguagem e de sua historicidade. Ela é um possível dos vestígios deixados pelas filiações discursivas num tecido particular.

Courtine (2006), ao propor uma genealogia da Análise do Discurso, sugere, para trabalhar a "espessura histórica" da discursividade, a busca de uma articulação entre discursos, imagens e práticas, considerando que ao discurso verbal integram-se as práticas não-verbais, "em que o verbo não pode mais ser dissociado do corpo e do gesto, em que a expressão pela linguagem se conjuga com a expressão do rosto, em que o texto torna-se indecifrável fora de seu contexto, em que não se pode mais separar linguagem e imagem." (2006, p. 57).

Essa preocupação traz à baila o tema do ethos, cuja lembrança flui, remontando, até a Grécia. Daí ser importante retomar todos esses fios para uma costura adequada do tema dos gestos e subgestos, tal como sugerido por Saramago em seu romance.

Saramago, por seu narrador, chega a preconizar a área de estudo dos subgestos como um ramo fecundo da ciência semiológica (cf. p. 47). Para exemplificar, transcrevo um recorte da obra (contexto: $\mathrm{O}$ personagem, um professor de História de ensino médio, participa de uma reunião em seu colégio e faz uma proposta quanto ao modo de ensino de sua disciplina):

Os efeitos da perorata foram os de sempre, suspiro de mal resignada paciência do director, trocas de olhares e murmúrios entre os professores. O de Matemática também sorriu, mas o seu sorriso foi de amistosa cumplicidade, como se dissesse, Você tem razão, nada disto é para levar a sério. O gesto que Tertuliano Máximo Afonso lhe enviou meio disfarçadamente do outro lado da mesa significava que agradecia a mensagem, porém, ao mesmo tempo, algo que ia junto e que, na falta de um termo melhor, designaremos por subgesto, recordava-lhe que o episódio do corredor não fora de todo esquecido. Por outras palavras, ao passo que o gesto principal se mostrava abertamente conciliador, dizendo, O que lá vai, lá vai, o subgesto, de pé atrás, matizava, Sim, mas não tudo. (2006, p. 45; grifos meus)

\footnotetext{
9 Julga-se que a visão da linguagem como "ação" (intencional) tenderia a apagar a potencialidade da interpretação - a ação suporia um dizer manifestado em sua transparência.
} 
Associado ao subgesto, o narrador de Saramago acrescenta o subtom, falando de outra cena:

Desta vez não foi um subgesto, mas sim um subtom, um harmônico, digamos, o que veio a dar nova força à incipiente teoria acima exposta quanto à importância que deveríamos dar às variações, não só segundas e terceiras, mas também quartas e quintas, da comunicação, tanto a gestual como a oral. (2006, p. 47-48)

Este trecho de Bakhtin (2003, p. 391) corrobora aquilo que a sensibilidade do escritor observa:

Papel excepcional do tom. [...] O aspecto menos estudado da vida do discurso. Não é o mundo dos tropos, porém o mundo dos tons e matizes pessoais, mas não em relação aos objetos (fenômenos, conceitos), e sim ao mundo das personalidades dos outros. O tom não é determinado pelo conteúdo concreto do enunciado ou pelas vivências do falante mas pela relação do falante com a pessoa do interlocutor (com sua categoria, importância, etc.).

Esse processo "mágico" de tematizar os enunciados está explicitado também no capítulo sobre tema e significação na língua em Marxismo e filosofia da linguagem, quando o acento apreciativo é destacado para mostrar:

a) que é uma parte da enunciação e que distingue enunciados aparentemente iguais em sua formulação apenas linguística;

b) que uma significação objetiva só se forma pela apreciação, e evolui com ela (BAKHTIN/VOLOSHINOV, 1979, p. 118-122).

Há uma referência, em Clark e Holquist (1998, p. 99), ao uso do "subtom de contabilidade" em Bakhtin em seu projeto de "arquitetônica"; ele está especificamente vinculado ao uso de muitos neologismos que se formam metaforicamente. No caso da contabilidade, trata-se da concepção de consciência, que Bakhtin descreve como unida à existência por ações; o existir humano aparece como postuplenie (entrar, incorporar-se). Mas uma sugestão posterior para postuplenie é "entrada / receita", como em contabilidade, o que traz a compreensão de que o ingresso na existência se faz por atos, pelos quais cada um deve responder. ${ }^{10}$

${ }^{10}$ Este é também um bom exemplo para mostrar como a realidade é vista diferentemente considerando a diversidade de línguas - tema desenvolvido por Flusser (2007) em Lingua e realidade. 
Esse subtom é remetido diretamente ao trabalho de Bakhtin como guarda-livros durante seu exílio, mas há outras sugestóes possíveis a partir daí: por um lado, é um exemplo do entrelaçamento da cultura e da vida - mostrando que a atividade da consciência transforma o que já "está alì"; por outro, em extensão, os subtons (e os subgestos, nos termos de Saramago) são produzidos e refinados com recursos verbais e não-verbais (incluindo as formulações metafóricas), tendo como resultado camadas de variação de sentido cujos vetores podem ser múltiplos. Isso tudo, conforme o destaque de Bakhtin (citação acima), em função da "relação do falante com a pessoa do interlocutor". Não somos apenas seres-de-linguagem, mas seres-de-linguagem-com, se posso assim expressar.

Em função desse contexto, que merece exploração cuidadosa, cabe dizer um mínimo necessário sobre a noção de ethos, a que se tem dado tanta atenção nos últimos anos. Vou fazer referência à abordagem de Maingueneau (2005), no campo da análise do discurso. $\mathrm{O}$ autor articula ethos à cena de enunciação, na qual dá destaque à relação corpo / discurso. Daí a noção associada de incorporação (que se vê matizada em Bakhtin, com referência à existência humana): o ethos estabelece relação entre um discurso e seu destinatário (chamo a atenção sobre isso remetendo à insistência de Bakhtin sobre o papel do tom, cujo sentido implica a presença do interlocutor). Em sentido estrito, o ethos está amarrado à enunciação.

Maingueneau estabelece que qualquer forma discursiva, não apenas a oral, tem "uma vocalidade específica" (tom) associada a uma fonte enunciativa. Com a audição ou a leitura por um coenunciador, o discurso proferido "dá corpo" ao enunciador - uma instância subjetiva que funciona como fiador [garant], que estimula o coenunciador a fazer uma representação e a atribuir igualmente um caráter ao fiador (certos traços psicológicos). ${ }^{11}$ Isso ocorre com base em experiências pessoais e estereótipos já estabelecidos nas comunidades. De outra parte, o coenunciador pode incorporar esquemas do fiador, buscando identificação com sua forma de estar no mundo, aderindo àquele discurso, eventualmente incorporando-se àquela comunidade (se se tratar de um chamado). Ele tem, nos termos de Bakhtin, uma atitude responsiva - que

\footnotetext{
${ }^{11}$ É claro que Maingueneau reconhece que há diferença entre um ethos oral (no sentido de uma presença imediata do enunciador-fiador) e um ethos escritural (em que o trabalho de interpretação do destinatário se faz apenas por indícios textuais). Para detalhes, consulte-se o autor.
} 
também pode ser, bem entendido, a de rejeição. Enfim, os enunciados trazem índices modais, qualquer que seja sua forma de expressão (verbal, imagética, sonora, gestual), produzidos e interpretados.

O que me parece importante nessa perspectiva é que o destinatário não é um consumidor passivo. O texto não é para ser contemplado, diz Maingueneau, "ele é enunciação voltada para um coenunciador que é necessário mobilizar para fazê-lo aderir 'fisicamente' a um certo universo de sentido" (2005, p. 73). Ou seja, esse coenunciador é estimulado pelo texto a identificarse com a movimentação de um corpo historicamente marcado por certos valores. Uma última observação sobre o ethos é que ele se diversifica em função dos tipos de discurso (filosófico, político, publicitário...) e dos gêneros (artigo de opinião, artigo científico, sermão...) dos diversos campos ou esferas.

Para ancorar essas consideraçóes, lembre-se a proeminência do corpo como valor no espaço da criação humana, tal como Bakhtin o apresenta em A forma espacial da personagem (BAKHTIN, 2003).

\section{A rede das relações pedagógicas: conhecimento e ética}

A partir daqui, gostaria de refletir sobre as consequências pedagógicas para quem, como nós, está implicado na "conversação" educacional; exponho em dois pontos as questóes essenciais, explicitadas nas subseçôes que seguem: a) ensino sem compreensão; b) apreciação valorativa, atravessando a linguagem verbal e a não-verbal.

\section{O ensino sem compreensão}

Como entender o ensino sem compreensão como critério externo e falso do conhecimento, sem assunção de conhecimento no mundo da vida (Bakhtin, mundo da cultura e mundo da vida) - ritual sem sentido? "A palavra quer ser ouvida, entendida, respondida e mais uma vez responder à resposta, e assim ad infinitum." (BAKHTIN, 2003, p. 334). "Chamo sentidos às respostas a perguntas. Aquilo que não responde a nenhuma pergunta não tem sentido para nós." (BAKHTIN, 2003, p. 381).

Essa postura, que tem caráter ético e estético, está presente em Bakhtin, como destaca Ponzio (2008), desde suas primeiras explorações filosóficas, quando reflete sobre Kant e o neokantismo em Para uma filosofia do ato, expressando sua própria concepção sobre a responsabilidade dos atos humanos relativamente aos outros: 
[...] trata-se de colocar o outro como imprescindível dentro de uma arquitetônica dialogicamente estruturada que encontra expressão na sua palavra e que requer da parte do eu a posição de calar e escutar, que requer uma posição de não-indiferença de participação, de compreensão respondente (PONZIO, 2008, p. 257).

A "arquitetônica" de Bakhtin implica a responsabilidade (respondibilidade) dos atos individuais relativamente a tudo o que compóe o mundo:

Cada um de nós ocupa um lugar e um tempo únicos na vida, uma existência que é concebida não como um estado passivo, mas ativamente, como um acontecimento. Eu calibro o tempo e o lugar de minha própria posição, que está sempre mudando, pela existência de outros seres humanos e do mundo natural por meio dos valores que articulo em atos (CLARK; HOLQUIST, 1998, p. 90).

É nesse sentido que a ética não pode ser restrita a princípios abstratos, e que o "eu" na concepção de Bakhtin só se sustenta em relacionamento tenso com os outros "eus" (alteridade). Em contraposição a um todo mecânico, "um todo arquitetônico é imbuído da unidade advinda do sentido, estando suas partes articuladas internamente, de um modo relacional que as torna interligadas e não alheias umas às outras, isto é, constitutivamente" (SOBRAL, 2005, p. 110).

A implicação aqui é que ensinar sem que haja compreensão gradual por parte do outro restringe o ensino a um desfilar de conhecimentos cuja apreensão dependerá unicamente desse outro - é o fazer calar, enunciar as verdades e "o melhor" sem a crítica, sem a palavra alheia. Vou evocar neste ponto um comentário de Deleuze para Foucault:

Se as crianças conseguissem que seus protestos, ou simplesmente suas questóes, fossem ouvidos em uma escola maternal, isso seria o bastante para explodir o conjunto do sistema de ensino. [...] As crianças sofrem uma infantilização que não é a delas. (apud FOUCAULT, 1989, p. 72).

Para Deleuze, como o sistema é frágil, nada pode suportar, e por isso mesmo usa a força da repressão. Daí que, para ele, seguindo uma lição fundamental de Foucault, falar insistentemente pelos outros (os mais interessados em certas questôes) é uma atitude indigna, quando esses "outros", com sua experiência de vida, têm algo a dizer, e apesar disso sua possibilidade de manifestação é tolhida. Falar pelos outros, em circunstâncias precisas, pode ser um ato valorizado e necessário em nossa sociedade, mas é necessário também que os implicados nele tenham feito sua própria manifestação, legitimando esse ato. Encontramos em Bakhtin (1997, p. 59, grifo do autor): "A verdade 
sobre o homem na boca dos outros, não-dirigida a ele por diálogo, ou seja, uma verdade à revelia, transforma-se em mentira que o humilha e mortifica caso esta lhe afete o 'santuário', isto é, o 'homem no homem'” - ou seja, capaz de significar-se a si mesmo, para o outro (enlaçamento de consciências). O homem reificado, na perspectiva monológica, liberta-se, transforma-se no homem dialogal. E a compreensão, aí, é o limite do diálogo concreto, impregnado do acento apreciativo.

Só se chega a uma vida humana autêntica pelo enfoque dialógico; é aí que cada um responde por si mesmo, sem precisar de outra consciência iluminada, avessa à escuta. Mas essa perspectiva exige coragem e responsabilidade pelos atos de quem quer que seja. E é difícil suportar o que se possa dizer de nós que não desejamos ouvir. Certamente é mais fácil fechar-se na perspectiva monológica e assumir que cabe ao outro escutar, sobretudo se de um lado se assume a prerrogativa da competência, institucionalmente outorgada. Mas cabe o alerta: "Para a palavra (e consequentemente para o homem) não existe nada mais terrível do que a irresponsividade" (BAKHTIN, 2003, p. 333). ${ }^{12}$

Vilém Flusser, filósofo que já referi (ver nota 2), usa o termo-chave conversação para indicar o fluxo da língua em fios na formação do intelecto e na construção da realidade:

O intelecto sensu stricto é uma tecelagem que usa palavras como fios. O intelecto "sensu lato" tem uma ante-sala na qual funciona uma fiação que transforma algodão bruto (dados dos sentidos) em fios (palavras). A maioria da matéria-prima, porém, já vem em forma de fios (2007, p. 40).

A língua como um todo é a soma das conversações e dos intelectos em conversação através das idades. [...] O intelecto em conversação conserva e aumenta o território da realidade. Realizando-se, realiza (2007, p. 50$).^{13}$

\footnotetext{
${ }^{12}$ Todorov $(1981$, p. 171, 172) observa como é impressionante ver o teórico do diálogo, um homem para quem a ausência de resposta é o mal absoluto, sofrer a má sorte de nunca receber resposta (referência à publicação sempre tardia de suas obras); e se pergunta se a teoria do dialogismo não teria nascido justamente do desejo de compreender o estado insuportável da ausência de resposta.

${ }^{13}$ A realidade se realiza nas línguas. "Há tantos sistemas categoriais, e, portanto, tantos tipos de conhecimento, quantas línguas existem ou podem existir." (2007, p. 52). Flusser, assim como Benveniste (Categorias de pensamento e categorias de língua, em Problemas de linguística geral, v. 1), apontou o defeito da categorização universal de Aristóteles para o pensamento, que o fez como tal porque pensava por
} 
Faço esse comentário para aproximá-lo de Bakhtin. Para mostrar a projeção da língua em relação à realidade, Flusser traçou um gráfico em forma de globo com um eixo de projeção que vai (verticalmente) do "silêncio inautêntico" em direção ao "equador da realidade" em várias camadas, batizadas como "balbuciar", "salada de palavras", "conversa fiada". Imediatamente acima do equador da realidade fica a camada da "conversação" (centro autêntico da língua fazendo-se: interação humana, contrapondo-se à conversa fiada), seguida da camada da "poesia" e da camada da "oração". Essas três últimas projetam-se em direção ao silêncio autêntico - limite do dizível. Quer dizer: as línguas surgem do nada e procuram o nada. "A grande conversação da qual participamos e que é toda a realidade vem do nada [o indizível] e trata do nada [o indizível]." (FLUSSER, 2007, p. 132).

É impossível explicar neste espaço, ainda que sinteticamente, como o filósofo vê essas camadas. Para meus propósitos, focalizo a camada da conversação, na qual, segundo Flusser, o "clima" é de intelectos realizados pelo contato com outros. "Os intelectos são abertos uns para os outros, são reais não por estarem aqui (Dasein), mas por estarem juntos (Mitsein)" (p. 139). A ciência, para Flusser, é uma forma desenvolvida e concentrada de conversação. Contrariamente, na simples conversa (fiada), os "intelectos" (ainda ou já) não apreendem nem compreendem, e refletem informações mecanicamente, distorcendo-as nesse processo. São conversações frustradas, vazias.

É nesse sentido que, no contexto pedagógico, quero compreender a arquitetônica bakhtiniana: receando, por um lado, que se possa estar recusando a palavra ao outro em formação institucional, e por isso mesmo bloqueando sua capacidade de compreensão e a oportunidade de estar junto, conversando.

\section{Apreciação valorativa atravessando a linguagem verbal e a não-verbal}

Este tópico é o acompanhamento necessário do anterior: diz respeito à captação dos subgestos e dos subtons na relação professor / aluno, nas trocas didáticas (ethos) - em suma, a apreciação valorativa atravessando a linguagem verbal e as outras modalidades de expressão. Esclareço que se trata aqui mais especificamente das atividades pedagógicas presenciais, sem com isso descartar as modalidades do "estar junto" à distância.

meio da língua grega. Como filósofo, Flusser parte da fenomenologia husserliana, para, diz ele, reconquistar a ingenuidade em face da língua, pondo entre parênteses os conhecimentos historicamente acumulados. 
Como em qualquer situação interlocutiva, mesmo naquelas em que já se atingiu uma familiaridade que permite certa distensão, trata-se, nas relações pedagógicas, de vários eus para os quais os outros são necessários e ao mesmo tempo diferentes, ou desconhecidos, ou estranhos e mesmo inimigos ameaçadores (o que todo professor pode ser, aos olhos dos alunos que já consumiram estereótipos, e estudantes podem ser entre si).

Essa circunstância e a situação específica de um encontro "forçado" institucionalmente levam a pesadas responsabilidades de uma parte e de outra, sobretudo considerando que, em princípio, sabe-se por que se está em tal espaço. Até que as imagens prévias vão se ajustando e haja certo acordo de "conversação" envolvendo conhecimentos, tarefas e avaliações, é comum que haja um clima de atenção a tudo que possa manifestar concordância ou discordância (e suas facetas) - e nesse clima instável se definem os vínculos interacionais. É aqui que começa a ação e resposta, com nova atitude responsiva e assim por diante, aos enunciados proferidos nas situaçóes específicas do acordo pedagógico: com os gestos e subgestos, os tons e subtons, a dinâmica corporal - que tematizam, em seu conjunto, a produção dos sentidos e o jogo das interpretações e reações.

A atenção a esses elementos, nesta perspectiva, tem duas vertentes e consequências associadas:

1) cabe compreendê-los em função da responsabilidade de uma parte e outra no processo de interação para formação específica, dadas as posições subjetivas em jogo;

2) cabe mostrar o funcionamento de todos esses gestos e tons para o relacionamento humano no mundo da cultura e da vida, especialmente se pessoas estão sendo formadas para serem formadoras.

\section{Considerações finais para um reinício}

Volto, neste ponto, ao nicho em que os gêneros fazem sentido no quadro epistemológico das propostas do Círculo de Bakhtin, em toda a sua heterogeneidade. Não tratei, neste trabalho, dos gêneros em sua singularidade nas esferas sociais. Quis, antes, atribuir-lhes sentido teórico e metodológico, tirar-lhes a eventual avaliação de apenas "ser modismo", e penso que esta passagem de Voloshinov dá a isso um peso particular, quando especifica a estrutura do enunciado: 
[...] é precisamente a diferença das situaçōes que determina a diferença dos sentidos de uma única e mesma expressão verbal. A expressão verbal - o enunciado - não se limita a refletir passivamente a situação; ele constitui, com efeito, sua resolução, realiza sua avaliação, e representa ao mesmo tempo a condição necessária de seu desenvolvimento ideológico vindouro (VOLOSHINOV, 1981, p. 303, grifos do autor, tradução minha).

Assim, ao pensar nos atos de caráter educacional, num campo de trabalho em que condições específicas e finalidades serão refletidas nos enunciados, exigindo um planejamento que não ignore os gêneros do discurso, vejo que a responsabilidade pelo ensino e pela aprendizagem se traduz, na cultura vivida, pelo empenho em não ser a consciência centralizadora que fecha os ouvidos às vozes, em vez de orientá-las para a grande conversação das ciências e da arte. $\mathrm{O}$ silenciamento pode ser mesmo ruidoso, porque haverá uma válvula de escape, manifestação de resistência por meio de canais alternativos. Uma consequência funesta do silenciamento será a reprise, mais adiante, das atitudes monológicas - ou seja, do tratamento recebido durante a formação escolar / acadêmica. O reconhecimento dos gêneros passa por fazê-los funcionar:

a) do ponto de vista da pesquisa, como real objeto de estudo, e não apenas como critério de delimitação de dados de pesquisa, como observa Rodrigues (2004, p. 435); e

b) do ponto de vista do ensino, como real atividade que considera as características do enunciado, e não como simples entrada de tarefas restritivas e fragmentadas - também no intercâmbio professor/aluno, que é a experiência pedagógica imediata.

Minha experiência com formação de profissionais da educação, a partir de uma compreensão mais dialógica da cultura em geral e dos sujeitos particularmente, se tem realizado com parcial sucesso e parcial fracasso. Tanto um quanto outro é verificável, de modo geral, respectivamente pela aproximação e pelo distanciamento. O parcial sucesso se tem verificado quando há escuta, resposta e negociação, tendo como resultado um enlaçamento produtivo que alcança as metas do trabalho; isso é perceptível na avaliação recíproca e na autoavaliação. O parcial fracasso é perceptível até mesmo pelo distanciamento físico e pelo silêncio talvez desejado, como marca de resistência que pode eventualmente ser dirigida a todos os docentes, não especialmente a um. Também se demonstra pela tentativa do estudante em responder ao ensino sem envolvimento, sem autoria, até mesmo com apelo à cópia. Trata- 
se de fuga, que precisa ser compreendida, porque ocorre um isolamento que leva a uma subjetividade deteriorada, que não se dinamiza na forma do nós.

O sucesso responde por si: há abertura e amadurecimento, e concretizamse os objetivos. Cada fracasso reconhecido exige, porém, um retorno de avaliação. Esse retorno faz reevocar os pontos da reflexão assinalados neste trabalho, cada vez com novo aprofundamento e novos matizes: a persistência do monologismo, da consciência voltada para si; a necessidade de resistir para ter voz, pensar por si mesmo, ser autor; o discurso e as comunidades de discurso; o não-verbal nas relações comunitárias.

Voltando ao já conhecido conjunto de etapas do estudo da linguagem proposto por Bakhtin/Voloshinov, seu sentido se avoluma e se aprofunda. Compreendemos a inversão do estudo que vai da abstração gramatical (as formas da língua, em sua neutralidade) aos textos - estratégia que, afinal, não consegue atingir a realidade do enunciado. Percebemos que cabe compreender primeiro as esferas sociais onde as situaçóes concretas se apresentam com interação verbal e todos os fenômenos que, do corpo, emanam para a língua; e que cabe apreender, aí, as variadas enunciações que se manifestam como gêneros do discurso na vida e na criação ideológica. E só então, no tecido dos enunciados, se tornam significativas as formas da língua (BAKHTIN/ VOLOSHINOV, 1979, p. 110).

A atitude monológica diante de sujeitos não tratados como interlocutores sufoca o direcionamento ao outro e a expectativa de resposta (alternância) e as ressonâncias dialógicas sobre o que foi enunciado anteriormente, produzindo o efeito de meras paráfrases que lembram a natureza da oração, tal como num tratamento meramente linguístico. A vontade discursiva, o projeto de dizer precedente é malogrado, porque se desliga a língua da vida circundante, e a vida não pode insinuar-se na língua. Nessa correnteza, esmaece toda a força da cultura dialógica, que é sustentáculo dos gêneros.

Para finalizar, retomo as noçôes de comunidade implícita e comunidade imaginada - conforme Wertsch -, que utilizei para contextualizar a relevância teórica e metodológica dos gêneros em Bakhtin, e nas práticas em ambiente institucional.

Se as comunidades ganham existência por intermédio da linguagem; se éa linguagem que mantém a união das comunidades, sua vitalidade e o compromisso dos membros com suas práticas em vista de finalidades específicas, posso visualizar da seguinte forma a distinção (não dicotômica) de Wertsch, que viu a abordagem de Bakhtin como mais voltada para comunidades implícitas - 
focalizando os processos envolvidos na produção dos enunciados em sua multiplicidade e abertura:

a) a instituição educacional lida com pessoas em formação; como tal, tem seus regulamentos, que pressupóem valores localizados e transcendentes, em função de características culturais;

b) são os professores os executores dos programas disciplinares, com os estudantes;

c) as disciplinas se desenvolvem reunindo estudantes e professores em pequenas comunidades, inicialmente muito heterogêneas e fluidas;

d) os professores são agentes de agregação, de união e vitalização do conjunto, apesar de que, imaginariamente, todos estejam cientes do funcionamento dessas pequenas comunidades;

e) na prática, a responsabilidade com a produção e a escuta tem de considerar a heterogeneidade (meios, pessoas, falares, temas...).

Se esse exercício conseguir atingir uma considerável harmonia (não uniformidade) de interesses e responsabilidade, a pequena comunidade tende a aproximar-se das características de uma comunidade imaginada - ou seja, o amadurecimento na formação fornece instrumentos para a futura pertença a uma comunidade imaginada, cimentando a comunidade. Penso que é isso que se busca quando se trabalha com formação. Nesse contexto, caberia preencher o espaço-tempo entre o implícito e o imaginado.

\section{Referências}

ANDERSON, B. Imagined communities: Reflections on the origin and spread of nationalism. London: Verso, 1991.

BAKHTIN, M./VOLOSHINOV, V. N. Marxismo e filosofia da linguagem. São Paulo: Hucitec, 1979.

BAKHTIN, M./VOLOSHINOV, V. N. Speech genres and other late essays. Austin: University of Texas Press (edited by C. Emerson and M. Holquist, translated by V.W. McGee), 1986.

BAKHTIN, M./VOLOSHINOV, V. N. Problemas da poética de Dostoiévski. 2. ed. rev. Trad. Paulo Bezerra. Rio de Janeiro: Forense Universitária, 1997.

BAKHTIN, M. Estética da criação verbal. 4. ed. Tradução de Paulo Bezerra. São Paulo: Martins Fontes, 2003. 
BONINI, A. Reflexôes em torno de um conceito psicolinguístico de tipo de texto. DELTA, São Paulo, v. 15, n. 2, p. 301-318, 1999.

CHARAUDEAU, P.; MAINGUENEAU, D. (Dir.). Dictionnaire d'analyse $d u$ discours. Paris: Seuil, 2002.

CLARK, K.; HOLQUIST, M. Mikhail Bakhtin. Trad. J. Guinsburg. São Paulo: Perspectiva, 1998.

COURTINE, J.-J. Uma genealogia da análise do discurso. In:

Metamorfoses do discurso político: derivas da fala pública. São Carlos: Claraluz, [1992] 2006. p. 37-57.

ELLERBE, H. The dark side of Christian history. San Rafael, CA: Morningstar Books, 1995.

FOUCAULT, M. Os intelectuais e o poder. In: . Microfisica do poder. 8 ed. Rio de Janeiro, Graal, 1989. p. 69-78.

FLUSSER, V. Lingua e realidade. 3. ed. São Paulo: Anna Blume, 2007. [1. ed. 1963, Herder]

HEBECHE, L. Da consciência ao discurso: ensaio sobre Mikhail Bakhtin. Florianópolis: Editora Barba Ruiva, 2007.

HIRSCHKOP, K. O sagrado e o secular: atitudes perante a linguagem em Bakhtin, Benjamin e Wittgenstein. In: FARACO, C. A.; TEZZA, C.; CASTRO, G. de. Vinte ensaios sobre Mikhail Bakhtin. Petrópolis: Vozes, 2006.

HOUAISS, A. Dicionário eletrônico Houaiss da lingua portuguesa. Rio de Janeiro: Objetiva, 2001. 1 CD.

MAINGUENEAU, D. Ethos, cenografia, incorporação. In: AMOSSY, T. (Org.). Imagens de si no discurso: a construção do ethos. São Paulo: Contexto, 2005. p. 69-92.

ORLANDI, E. P. Interpretação: autoria, leitura e efeitos do trabalho simbólico. Petrópolis: Vozes, 1996.

PIMENTA, V. R. Gêneros textuais próprios da comunidade discursiva forense. SIMPÓSIO INTERNACIONAL DE ESTUDOS DE GÊNEROS TEXTUAIS, 4., 2007, Tubarão. Anais ... Tubarão: UNISUL, 2007. p. 2028-2040.

PONZIO, A. A revolução bakhtiniana: o pensamento de Bakhtin e a ideologia contemporânea. Coordenação de tradução Valdemir Miotello. São Paulo: Contexto, 2008.

RODRIGUES, R. H. Análise de gêneros do discurso na teoria bakhtiniana: algumas questões teóricas e metodológicas. Linguagem em (Dis)curso, v. 4, n. 2, p. 415-440, jan./jun. 2004. 
ROSENSTOCK-HUESSY, E. A origem da linguagem. Rio de Janeiro: Record, 2002.

SAGAN, C. Variedades da experiência cientifica: uma visão pessoal da busca por Deus. São Paulo: Companhia das Letras, [2006] 2008.

SARAMAGO, J. O homem duplicado. São Paulo: Companhia das Letras, 2006. SOBRAL, A. Ético e estético. Na vida, na arte e na pesquisa em Ciências Humanas. In: BRAIT, B. (Org.). Bakhtin: conceitos-chave. São Paulo: Contexto, 2005. p. 103-121.

SWALES, J. English in academic and research settings. Cambridge: Cambridge University Press, 1990.

TODOROV, T. TODOROV, T. Mikhä̈l Bakhtine - le principe dialogique. Suivi de Écrits du Cercle de Bakhtine. Paris: Editions du Seuil, [1930] 1981.

VOLOSHINOV, V.N. La structure de l'énoncé. In: TODOROV, T. Mikhaïl Bakhtine - le principe dialogique. Suivi de Écrits du Cercle de Bakhtine. Paris: Editions du Seuil, [1930] 1981. p. 287-316.

WERTSCH, J. V. Vygotsky and Bakhtin on community. 1998. Artigo retirado de circulação do site Bakhtin Centre: <http://www.shef.ac.uk/bakhtin/> . Acesso em: 17 jan. 2009.

Recebido em outubro de 2009. Aprovado em fevereiro de 2010. 